\title{
SELF-LIMITING ACUTE CLOSED-ANGLE GLAUCOMA WITH SEGMENTAL IRIS SHORTENING*
}

\author{
BY
}

\author{
CALBERT I. PHILLIPS AND DERRICK F. WOODHOUSE \\ Bristol Eye Hospital and Department of Ophthalmology, University of Bristol
}

THE purpose of this communication is to record a series of cases of acute closed-angle glaucoma which appear to have resolved permanently without operation because of shortening of a segment of the iris. This shortening of a segment of the iris has been great enough, we believe, in these cases to eliminate relative "pupillary block" and therefore iris bombé; enough residual angle has then opened, especially inferiorly, to allow adequate drainage of aqueous humour. Such a mode of resolution of acute closedangle glaucoma seems to be more common than was considered when its occurrence was mentioned previously (Phillips, 1956). The Figure shows a typical example.

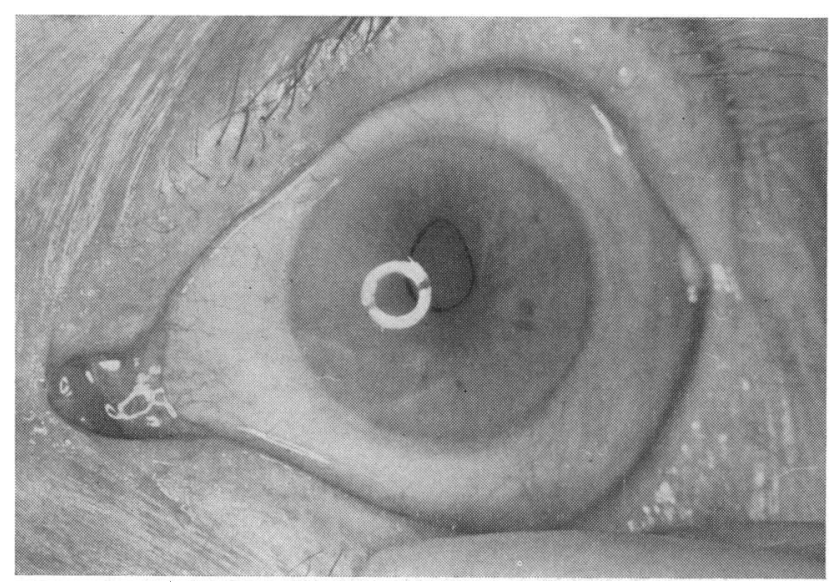

FIGURE.-Left eye of Case 1, showing a typical example of self-limitation of acute closed-angle glaucoma with shortening of a segment of iris and peaking of the pupil at 12 o'clock.

\section{Mechanism of Closed-Angle Glaucoma}

Although neurovascular instability may precipitate or complicate closed-angle glaucoma, a mechanical concept of the development of the disease now seems to be accepted (Chandler, 1952).

This disease affects eyes with inherited shallow anterior chambers, which explains their narrow angles; growth of the lens, by pushing the pupil forwards, accentuates both these attributes of the chamber. These eyes develop an abnormal

\footnotetext{
* Received for publication October 23, 1962.
} 
resistance to passage of aqueous through the pupil; the block increases as the crystalline lens grows in size and so ballooning of the iris (iris bombé) appears and becomes gradually more marked. This leads to increasing narrowness of the angle, especially superiorly, and eventually to closure. Closure of the angle, which implies occlusion of the trabeculae, starts superiorly and progresses gradually downwards on the nasal and temporal sides. Throughout this process the amount of closure may vary with such factors as pupil size, aqueous flow, and elasticity of the iris. Symptoms occur when enough of the trabecular meshwork is occluded by the periphery of the iris. This irido-trabecular contact tends to be converted to permanent goniosynechiae, especially if "subacute attacks of glaucoma" occur. The result is either acute closed-angle glaucoma or the insidious development of chronic closed-angle glaucoma, unless a peripheral iridectomy has been performed.

TABI़

CLINICAL PARTICULAG

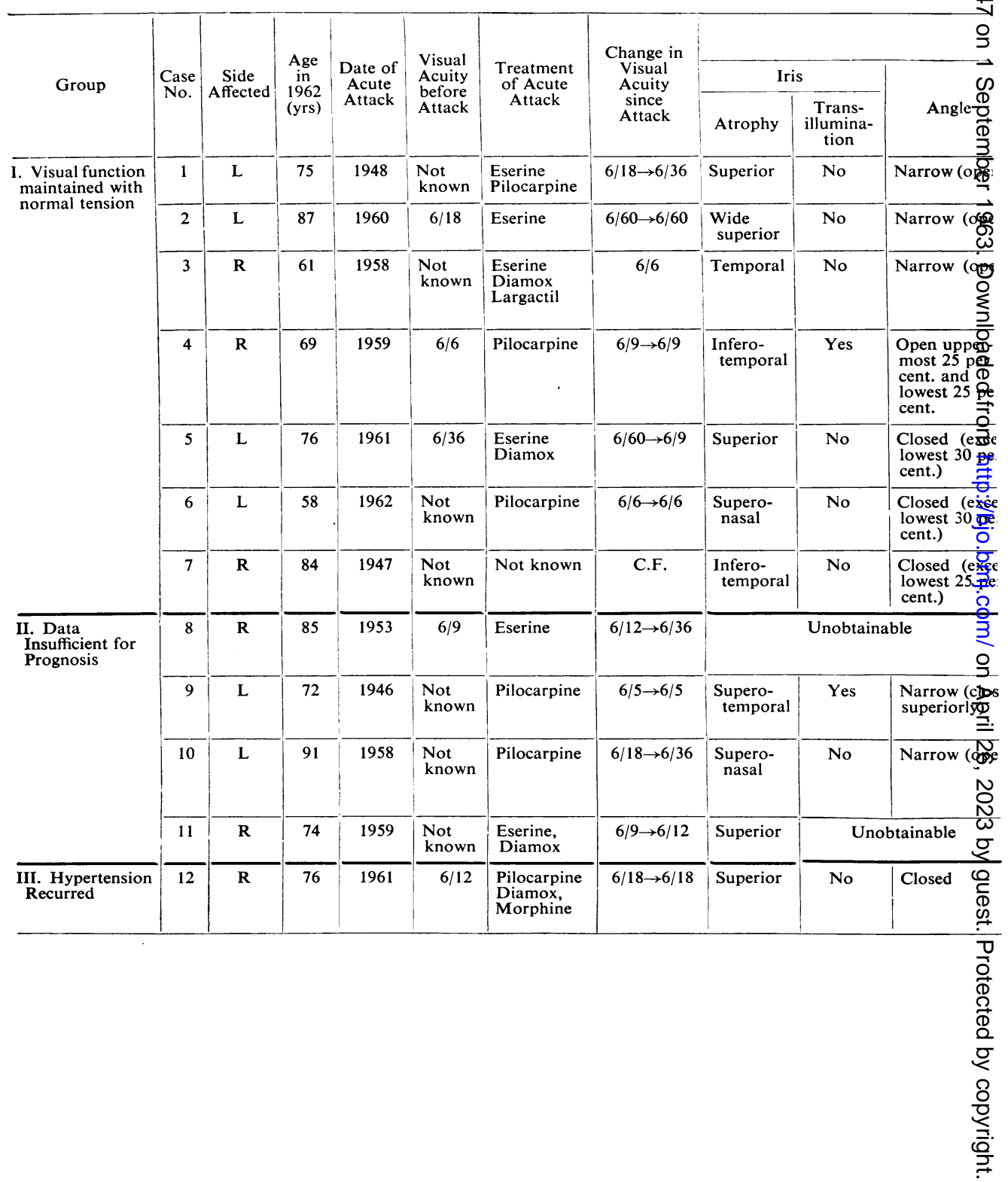




\section{Case Reports}

Details of the twelve unusual cases which have resolved "spontaneously", and in all but one case permanently, are recorded in the Table. These patients attended under the care of the consultants at Bristol Eye Hospital, but do not represent all the examples of this syndrome attending the hospital since 1946, the year in which the acute attack of the earliest case occurred. They are all patients who have happened to attend during the 6 months before the writing of this communication, or whose names were remembered by the staff. In December, 1961, and January, 1962, these patients were recalled for examination. Of the twelve patients, nine attended, one having died and two being bed-ridden.

One case (Group III, No. 12 in Table) is included to emphasize the importance

\section{i TWELVE PATIENTS}

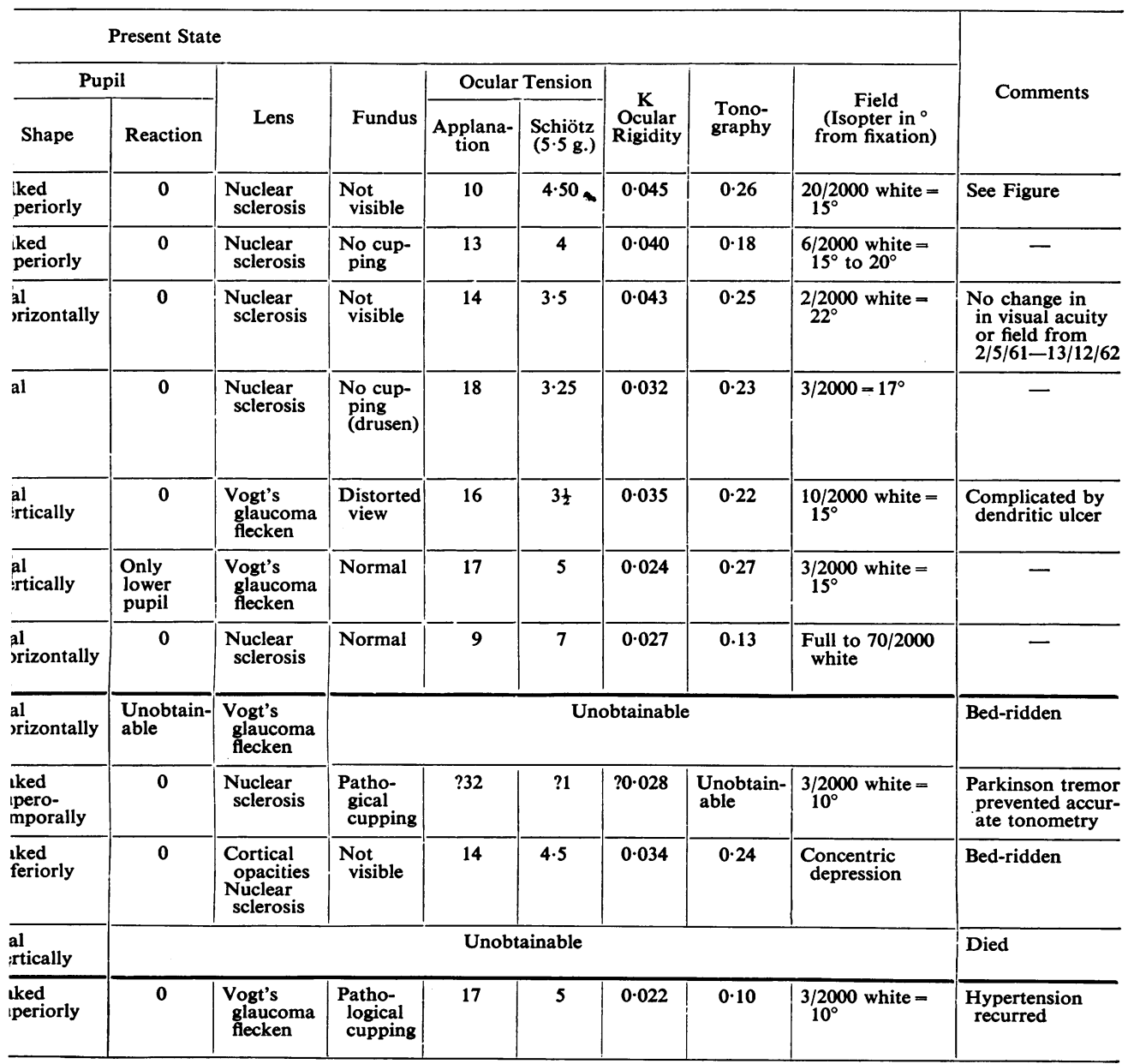


of careful surveillance for a recurrence of hypertension. In four cases (Group II, Nos 8-11) the data were not sufficient for any firm conclusions to be drawn, but it seemed probable that spontaneous resolution had occurred. The first seven cases (Group I, Nos 1-7) seem to justify the diagnosis of self-limitation.

Eucatropine outflow tests were negative in Cases 1, 4, and 6; a dark-room test was negative in Case 3. These tests, like tonometry and tonography on these cases, were done "off drops". Because of the previous infection with herpes simplex, although it preceded the acute attack by 14 years, no provocative test was done in Case 5. We did not succeed in recalling Cases 2 and 7 for further tests.

\section{Comments on Cases}

(a) In the treatment of the acute episode, miotics were universal and had been applied sometimes intensively and sometimes in lower doses according to the severity of the attack. Diamox had been used in only four cases, so that this new factor in treatment would not account entirely for the type of resolution here described.

(b) Changes in the visual acuity and visual fields after the acute attack varied considerably. The onset of cataract made it difficult to assess the progress of any deterioration.

(c) Iris atrophy occurred usually in, the supero-temporal half, a finding which may be causally related to the fact that the angle usually starts to close in that region.

(d) The area of iris atrophy transilluminated in only two cases and in only a small part of the atrophic area. This accords well with the description of the pathology of iris atrophy in acute glaucoma, which affects mainly the stroma and leaves the pigmented epithelium virtually intact (Wolff, 1951; Samuels and Fuchs, 1952; Friedenwald and seven others, 1952). This is an important clinical point of difference from the glaucoma caused by "essential" iris atrophy, when the iris always transilluminates through the area of atrophy (Etienne, 1960).

(e) The pupil showed peaking (or an oval shape) in the direction of the segment of iris atrophy. It was possible in at least one case to see, with the slit-lamp microscope, a gap between the pupil and the lens.

$(f)$ The lens showed some opacity in all the cases examined; in four this conformed with the typical cataracta disseminata subepithelialis glaucomatosa or "glaucoma flecken" (Vogt, 1931; Jones, 1959). The opacity of the lens contributed considerably to the eventual visual defect.

(g) Tonography, uncorrected for ocular rigidity, was done with a Schiötz tonometer at $5.5 \mathrm{~g}$. (Moses and Becker's tables (1958) were used). Even in Group I, some of the results of tonography are near the threshold for field loss, and do not correlate well with the results of gonioscopy. An explanation may be trabecular damage which occurred during the acute attack so that aqueous outflow could not occur in some areas in spite of an open angle; 
however, it must be admitted that posterior trabecular synechiae are sometimes difficult to see, especially nasally and temporally, with a Goldmann gonioscope.

(h) Ocular rigidity was high in all but two patients. Even if a high degree of experimental error is present, this observation is interesting: the discrepancy between the applanation and Schiötz readings is probably due mainly to the fact that these eyes have a lower than average intra-ocular volume (and surface area of corneo-scleral envelope) and a smaller than normal radius of corneal curvature.

(i) The rationale of "self-limitation" has been applied in an attempt to produce a "medical iridectomy" in the acute phase in one case. A very small pledget of cotton wool soaked in phenylephrine 10 per cent. was applied on a glass rod to the limbus (after instillation of a local anaesthetic) superotemporally where the peak in the pupil seemed to be "aiming". Although some shortening of the related segment of iris did occur, it was slight and no sign of resolution of tension appeared.

\section{Discussion}

Segmental degeneration of the iris, with distortion of its structure into whorls, is well-known in acute closed-angle glaucoma (Vogt, 1930, 1931; Sugar, 1957; Haas, 1959). These authors do not relate the atrophy of the iris to the fall in tension which occasionally occurs, or to the appearance of the angles in these eyes.

Our suggested mechanism of evolution of cases showing self-limitation is presented at the beginning of this communication, and these factors with other possibilities are discussed below:

(1) Shortening of a segment of iris is usually confined to its superotemporal half and is sufficient to minimize the pupillary block and reduce iris bombé. This will be effective in opening the angle and reducing tension only if the goniosynechiae are not too extensive or too firmly adherent (Section 4 below). In our cases necrosis had usually occurred in a segment of iris based on the narrowest part of the angle; the base of the segment was included in an area of permanent goniosynechiae. This relationship seems constant, but is difficult to explain; possible factors (single or in combination) - may be:

(a) Peaking and traction forwards of part of the pupil by peripheral anterior synechiae.

(b) Interference with blood or nerve supply by goniosynechiae, which may produce infarction of the iris in the related segment (Ridley, 1961). Angulation of the periphery of this part of the iris may make the branches of the circulus arteriosus major more easily occluded when an acute attack occurs. The minor 
circle does not usually provide a sufficient anastomosis as its anatomical completeness varies and some of its vessels may be obliterated (Duke-Elder and Wybar, 1961).

(c) Following infarction, as in (b) above, fibrosis of the iris stroma may eventually occur (Friedenwald and others, 1952) in the affected segment, which may produce contraction with peaking of the pupil.

(d) Following infarction, the related sector of the sphincter pupillae may also be destroyed with consequent enlargement of the pupil (Winstanley, 1961); one of Winstanley's cases seems unusual in that an inferior segment of iris has shortened.

(2) Dehiscences of the iris may occur following necrosis and thus allow enough aqueous to by-pass the pupil and relieve the iris bombé (Winstanley, 1961). This is not supported by our clinical observations, which suggest that the pigment epithelium is usually intact.

(3) Rupture of the pupil may occur in the atrophic area, especially if miotics have been used.

(4) Even if pupillary block and therefore iris bombé resolve by shortening of a segment of iris, the eye will avoid chronic closed-angle glaucoma only if enough angle can open to allow adequate drainage of the inflowing aqueous. If irido-trabecular contact has had time to be converted to goniosynechiae, these would be expected to be most recent inferiorly so that it is not surprising to find residual open angle inferiorly in almost all the cases recorded here. An element involved may be that the contracted segment of iris may pull the whole pupil upwards, especially if miotics be used, so that the fresh inferior goniosynechiae are broken more actively than merely by resolution of iris bombé. Close supervision of all these cases is required lest residual goniosynechiae (or trabecular damage and blockage due to débris produced during the acute attack) are sufficient to cause insidious chronic closed-angle glaucoma, which may require a drainage operation. This supervision is often made more difficult by the frequent occurrence of increasing cataract. Applanation tonometry may be the best guide to progress in such cases.

(5) Some reduction of the inflow of aqueous humour because of atrophy of the ciliary body (possibly segmental) may result from the acute attack. Although the ocular tension appears normal (see Table), the results of tonography indicate a reduced outflow; the discrepancy might be due to a reduced inflow because of atrophy of the ciliary epithelium after the acute attack. However, the values of outflow recorded must be accepted with caution because:

(a) No correction has been applied for variation from normal in the corneal curvature, intra-ocular volume, surface area of the corneo-scleral envelope, and volume of the intra-ocular blood-cushion which these eyes may be expected to have;

(b) No continuously-recording tonometer was available. 
Deutsch (1959) attributed the resolution of a case of closed-angle glaucoma to atrophy of the ciliary body, since the angle remained completely closed. Poos (1953) presented three similar cases and attributed simultaneous atrophy of the iris and ciliary body to a reduction in the blood-flow in the circulus arteriosus major.

(6) Why did the cases recorded here resolve "spontaneously" whereas the vast majority do not? We have no satisfactory explanation, but the process might be related to the presence in the former of a greater disparity than usual between the upper and lower parts of the angles; permanent goniosynechiae may have formed superiorly long enough before involvement of the inferior angle to allow some "peaking" to start in advance of the acute attack. Furthermore, the pre-existing peak may form a fixed point towards which the pupil is contracted by miotics, leading to an "active" opening of the angle inferiorly.

\section{Summary}

A series is described of twelve cases of acute closed-angle glaucoma, of which seven definitely (and four probably) have permanently resolved without operation because of shortening of a segment of the iris; pupillary block and therefore iris bombé have thus been eliminated "spontaneously". It is emphasized that there is a serious possibility that chronic closed-angle glaucoma may supervene, as in one case in this series, so that close supervision of such patients is necessary lest a drainage operation be required.

The segmental shortening usually takes place in the upper half or two-thirds of the iris; the angle is narrowest superiorly where it tends to be the first to suffer irido-trabecular contact or formation of goniosynechiae. The somewhat obscure details of the relationship, if any, between these two facts are considered in the discussion.

It is not known why these cases should achieve "self-limitation" instead of suffering the commoner fate of acute closed-angle glaucoma or insidious chronic closed-angle glaucoma. Perhaps they have a greater disparity than usual between the upper and lower angles (the upper being almost invariably narrower) so that permanent goniosynechiae may have formed superiorly long enough before the acute attack to produce some "peaking" of the pupil which is continued in the acute attack; also, the pre-existing peak may form a fixed point towards which miotics contract the pupil, leading to an "active" opening of the angle inferiorly.

\section{REFERENCES}

Chandler, P. A. (1952). Arch. Ophthal. (Chicago), 47, 695.

Deutsch, A. R. (1950). Amer. J. Ophthal., 48, 400. Duke-ElDER, S., and WYBAR, K. (1961). "System of Ophthalmology", vol. 2, p. 350. Kimpton,
London. 
ETIENNe, R. (1960). Ann. Oculist. (Paris), 193, 224.

Friedenwald, J. S. and Seven OTHERS (1952). “Ophthalmic Pathology”, p. $305 . \quad$ Saunders, Philadelphia.

HAAS, J. S. (1959). "Symposium on Glaucoma", ed. W. B. Clark, p. 123. Mosby, St. Louis. JONES, B. R. (1959). Trans. ophthal. Soc. U.K., 79, 753.

Moses, R. A., and BeCKER, B. (1958). Amer. J. Ophthal., 45, 196.

PHILlIPS, C. I. (1956). Brit. J. Ophthal., 40, 136.

Poos, F. (1953). Klin. Mbl. Augenheilk., 123, 277.

RIDLEY, H. (1961). Trans. ophthal. Soc. U.K., 81, 38.

Samuels, B., and Fuchs, A. (1952). "Clinical Pathology of the Eye", p. 246. Hoeber, New York.

Sugar, H. S. (1957). "The Glaucomas", 2nd ed., p. 216. Hoeber-Harper, New York. VoGt, A. (1930). Klin. Mbl. Augenheilk., 85, 586.

(1931). "Lehrbuch und Atlas der Spaltlampe mikroscopie des lebenden Auges", vol. 2, p. 565. Springer, Berlin.

Winstanley, J. (1961). Trans. ophthal. Soc. U.K., 81, 23.

WolfF, E. (1951). "A Pathology of the Eye", 3rd ed. Lewis, London. 